Putin, V. V. (1999) Rossija na rubezhe tysjacheletij. Nezavisimaja gazeta, 30 December, pp. 1-2. (In Russ.).

Putin: nacional'naja ideja v Rossii - jeto patriotizm (2016). RIA Novosti, 3 February [online] Available at: https://ria.ru/society/20160203/1369184806.html (acces date 02.12.2016). (In Russ.).

Sevast'janov, A. N. (2008) Jetnos i nacija. Moscow, Knizhnyj mir. 192 p. (In Russ.).

Semenenko, I. S. (2012) Politicheskaja nacija, nacional' noe gosudarstvo i grazbdanskaja identichnost': na putiv global'nyj mir. Politicheskaja identicbnost' $i$ politika identicbnosti: v 2 tomah / ed. by I. S. Semenko. Moscow, Rossijskaja politicheskaja jenciklopedija (ROSSPJeN). Vol. 2. Identichnost' i social'no-politicheskie izmenenija v XXI veke. 471 p. Pp. 41-72. (In Russ.).

Soldatova, G. U. (1998) Psibologija mezhjetnicheskoj naprjazhennosti. Moscow, Smysl Publ. 389 p. (In Russ.).

Stefanenko, T. G. (2004) Jetnopsibologija: uchebnik dlja vuzov. Moscow, Aspekt Press Publ. 368 p. (In Russ.). Russ.).

Tishkov, V. A. (2010) Rossijskij narod: kn. dlja uchitelja. Moscow, Prosveshhenie Publ. 191 p. (In

Filosofskij jenciklopedicheskij slovar' (1989) / pod red. S. S. Averinceva. Moscow, Sovetskaja jenciklopedija Publ. 815 p. (In Russ.).

Hotinec, V. Ju. (2000) Jetnicheskoe samosoznanie. St. Petersburg, Aletejja Publ. 240 p. (In Russ.).

Hotinec, V. Ju. (2002) Jetnicheskaja identichnost' i tolerantnost'. Yekaterinburg, Ural'skii universitet Publ. 124 p. (In Russ.).

Submission date: 21.07 .2017

Инкижекова Мария Сергеевна - доктор философских наук, доцент, профессор кафедры общей психологии и гуманитарных дисциплин Уральского юридического института Министерства внутренних дел Российской Федерации. Адрес: 620057, Россия, г. Екатеринбург, ул. Корепина, д. 66. Тел./факс: +7 (343) 331-70-84. Эл. адрес: masha_ink@mail.ru

Inkizhekova Maria Sergeevna, Doctor of Philosophy, Associate Professor, Professor, Department of General Psychology and the Humanities, Ural Law Institute, Ministry of Internal Affairs of the Russian Federation. Postal address: 66, Korepina St., Yekaterinburg, Russian Federation 620137. Tel./fax:+7 (343) 331-70-84.E-mail: masha_ink@mail.ru

DOI10.17805/zpu.2017.4.5

\title{
Оценка качества реализации образовательной деятельности как воплощение постулатов философии качества
}

\author{
И. И. КОРЯГИНА, М. В. ЖУКОЛИНА
}

ИВАНОВСКАЯ ГОСУДАРСТВЕННАЯ МЕДИЦИНСКАЯ АКАДЕМИЯ МИНИСТЕРСТВА ЗДРАВООХРАНЕНИЯ

РОССИЙСКОЙ ФЕДЕРАЦИИ

В статье представлен анализ понятия «качество» в истории и современности, анализ подходов к проведению оценки качества образовательной деятельности в высшем учебном заведении и выработке интегральной концепции оценки качества. Методология исследования включает в себя анализ и синтез эмпирического опыта, методы включенного наблюдения и обработки накопленных данных. 
Сделан обзор становления понятия «качество» в истории философии, определены ключевые значения и эволюция смыслового наполнения. Определены проблемные поля в оценке качества, исходя из его философского понимания: несводимость качества к количественным характеристикам, представление о качестве как о постоянно улучшающейся величине, системность и многомерность качества. На пути оценки качества в образовательной сфере выделены уровни управления качеством образовательной деятельности от уровня высшего руководства, через уровни учебно-методического управления, факультетов и кафедр к базовым уровням преподавателя и студентов. На уровне высшего руководства представлены существующие практики по оценке качества образовательной деятельности со стороны органов государственной власти и независимой оценки качества, проанализирована возможность распространения данных методик на другие уровни образовательной деятельности.

Систематизированы применяемые на каждом уровне механизмы оценки качества образовательной деятельности и показана возможность их интеграции для получения максимально объективной оценки с учетом требований всех заинтересованных сторон.

Раскрыта результативность применяемых механизмов оценки качества образовательной деятельности и представлена возможность их интеграции в рамках системы менеджмента качества высшего учебного заведения.

Ключевые слова: качество; философия качества; управление качеством; оценка качества; уровни оценки; образовательная деятельность; структура образовательной деятельности

\section{ВВЕАЕНИЕ}

$\mathrm{O}$ ценка качества образовательной деятельности в высшем учебном заведении ставит перед нами ряд важных проблем. Во-первых, образовательная деятельность представляет собой многоплановый процесс взаимодействия субъектов образования. Поэтому для оценки качества образовательной деятельности необходимо учитывать как качество образовательных программ и реализующих их преподавателей (что обеспечивается их академической квалификацией), так и качество подготовки студентов (которое достигается на пути преодоления разрыва, существующего между средней и высшей школой, на пути учебно-профессиональной ориентации обучающихся и создания индивидуального образовательного маршрута). Важную роль в оценке качества образовательной деятельности играет качество инфраструктуры, зависящее от должного государственного финансирования и поэтому не всегда поддающееся влиянию со стороны субъектов образовательного процесса. Также важный аспект представляет собой оценка качества образовательной деятельности со стороны заинтересованных лиц - работодателей выпускников учебного заведения и профессионального сообщества.

Однако, прежде чем приступать к анализу многоплановой системы оценки качества образовательной деятельности, необходимо определить суть понятия «качество», провести корреляцию понятий «оценка» и «качество» с точки зрения современной философии качества. Понятие «оценка» в применении к антропогенным явлениям представляет собой установление значимости этих явлений, соответствия их определенным нормам и принципам, установленным человеческим сообществом. Отметим, что критерии оценки устанавливаются людьми в зависимости от ситуации и носят несколько субъективный характер, поэтому неприемлемо распространение процедуры оценивания на то, что не связано с социальной, антропогенной средой. Мера соответствия явления определенным нормам и принципам носит количественное выражение, и сама процедура оценивания связана с наделением объекта количественными характеристиками. 
ИСТОРИКО-ФИАОСОФСКИЙ АНААИЗ КАТЕГОРИИ «КАЧЕСТВО»

В истории человеческой культуры философские категории «количество» и «качество» неразрывно взаимосвязаны, но выступают как диаметрально противоположные характеристики предметов, явлений и процессов. «Количество» имеет числовое выражение, «качество» выражает некое свойство объекта, не поддающееся количественному исчислению, что переводит проблему оценки качества в ряд философских проблем.

Становление философской категории «качество» традиционно связывают с именем великого систематизатора философии Аристотеля. Однако вопрос о качестве был поставлен еще до Аристотеля в трудах стихийных материалистов Милетской школы и Гераклита Эфесского. Первые греческие философы связывали многообразие предметов и явлений природы с качественными переходами одной стихии в другую. Категория «качество» определяет сущность объектов действительности и их видовую принадлежность, она неразрывно связана с «вещным» миром и выступает как категория онтологии.

Аристотель определяет качество как то, «благодаря чему предметы называются такими-то» (Аристотель, 2016: 72), выделяя четыре разновидности качества. Таким образом, он первый переводит «качество» из сферы онтологии в гносеологию, связывая его с познанием человеком мира. В первом значении под качеством он понимает устойчивые свойства предмета, а во втором - преходящие, которые быстро изменяются, но и те, и другие свойственны непосредственно вещи. Третья разновидность качеств - «претерпеваемые», т. е. оказывающие воздействия на органы чувств человека, а четвертая разновидность представляет собой некий облик вещи, который позволяет выделить ее из внешнего мира и именовать. Последние две разновидности «качества» связывают данную категорию с процессом познания мира и фиксации результатов познания, усиливая «субъективность» данной философской категории.

Как совокупность признаков, выделяющих предмет из ему подобных, категория «качество» позволяет мыслить объект и осознавать его уникальность. В отличие от количественных изменений, характеризующихся уменьшением или увеличением некоего числа и носящих достаточно последовательный характер, качественные изменения представляют собой резкий переход между противоположными состояниями ( «тепло»- «холод», «сладость»- «горечь»). Аристотелевская линия исследований философских категорий, включая категорию «качество», продолжалась в схоластической философии.

Подлинным переворотом с изменением значения термина «качество» стал эмпиризм Аж. Аокка. Его учение о первичных и вторичных качествах связывает «качество» с чувственным опытом человека и усиливает субъективность данной категории

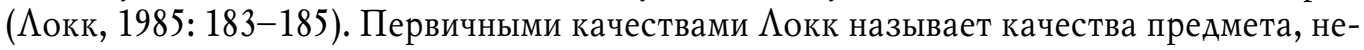
посредственно ему присущие и выделяющие его из остального мира: это такие качества, как пространственные характеристики, плотность и материал, состояние движения и покоя. Но больший интерес вызывают вторичные качества, которые мы чаще используем для характеристики предмета, хотя они не присущи самому предмету, а скорее характеризуют наше восприятие. Цвет, вкус, запах, звук - это результат действия наших анализаторов и фактически «навязываются» предмету в процессе познания. Таким образом, в философии Нового времени категория «качество» впервые осмысляется как оценочная категория, выводится из сферы онтологии и вкдючает гносеологический (познавательный) и аксиологический (ценностный) аспекты. 
И. Кант в «Критике чистого разума» относит категорию «качество»к четырем фундаментальным категориям рассудка наряду с категориями количества, отношения и модальности. Эти категории априорны, т. е. не выводятся из опыта, напротив, наряду с категориями чувственности и разума, категории рассудка создают некую матрицу, позволяющую упорядочить хаос чувственных впечатлений и систематизировать их (Кант, 2015). Эта систематизация, в свою очередь, придает частному ограниченному человеческому опыту значение необходимости и всеобщности. Применение этих категорий делает изучение мира систематическим и, по словам Канта, «служит достоверным наставлением или путеводной нитью» (Кант, 2008: 104).

Г. В. Ф. Гегель рассматривает «качество» как логическую категорию, лежащую в основе познания мира (Гегель, 2007). Именно раскрытие качественных характеристик предмета приближает к познанию сущности исследуемого объекта. При этом познание качественной стороны объекта движется от внешнего к внутреннему. Если «количество» выражает внешнюю определенность предмета, то «качество» - внутреннюю, сущностную. Количество характеризует множество и величину объекта, качество же - его сходство с другими объектами и отличие от них, выступая как системная характеристика. Эти категории связаны в диалектике Гегеля понятием меры, при достижении которой количественные изменения способны привести к изменениям качественным. Однако эти категории взаимонепереводимы: качество не имеет количественного выражения.

Понятие меры как границы, в рамках которой происходящие количественные изменения не влекут за собой качественных, играет очень важную роль в оценке качества. Необходимо определение этой меры, границы, до достижения которой количественные изменения не несут смысловой нагрузки, но при достижении которой мы фиксируем качественные изменения. Иначе мы можем обращать внимание на рост или падение количественных показателей, но эта информация не будет достойна внимания, если количественные изменения не оказывают влияния на качество исследуемых процессов.

\section{КАЮЧЕВЫЕ ПОСТУААТЫ «ФИАОСОФИИ КАЧЕСТВА» ХХ ВЕКА}

В XX в. происходит переход к практико-ориентированному подходу в понимании качества: «качество» трактуется не как онтологическая или гносеологическая категория, а как ценностная категория, как характеристика практической деятельности человека. Создание философии качества ознаменовало два важных момента. Во-первых, категория «качество» приобретает абсолютно положительное значение, говоря о качестве, подразумевают хорошее качество, что сужает смысловое поле данной категории. Во-вторых, «качество» окончательно становится оценочной категорией, что придает ей субъективность, но одновременно многомерность из-за множества оценивающих качество заинтересованных сторон. Так, У. Э. Аеминг, рассматривая категорию «качество» в разных аспектах человеческой деятельности, заключает, что у создателей и потребителей продукта при оценке качества продукта будут фигурировать принципиально разные критерии (Аеминг, 2007: 158-169). Необходим «операциональный» подход к оценке качества, способный превратить «качество»в объект практических исследований и измерений. На этом пути категория «качество» теряет смысловую нейтральность и сближается с понятием эталона: «качественный» означает «пригодный», «полезный», «надежный».

Первый из тех, кого теперь называют «американскими гуру качества», Аеминг формулирует 14 принципов управления качеством, которые становятся краеугольным камнем философии качества. 
1. Аобивайтесь постоянства цели - непрерывного улучшения продукции и услуг для достижения конкурентоспособности, сохранения бизнеса и создания новых рабочих мест.

2. Примите новую философию. Мы находимся в новой экономической эре. Западный менеджмент должен принять вызов и сознать свою ответственность, став лидером перемен.

3. Покончите с зависимостью от контроля качества. Устраните потребность в массовых проверках, прежде всего встраивая качество в продукцию.

4. Положите конец практике оценки и выбора поставщиков только на основе цены. Вместо этого минимизируйте общие затраты. Стремитесь найти единственного поставщика для каждого вида поставок на основе долговременных отношений лояльности и доверия.

5. Постоянно и непрерывно совершенствуйте систему производства и обслуживания, чтобы улучшать качество и производительность, а значит, беспрестанно снижать затраты.

6. Введите обучение на рабочих местах.

7. Учредите лидерство. Целью руководителей должна стать помощь людям, совершенствование станков и приспособлений, чтобы они работали лучше. Нужно пересмотреть методы руководства по отношению как к менеджерам, так и к производственным рабочим.

8. Изгоняйте страх, чтобы все могли работать эффективнее на компанию.

9. Разрушайте барьеры между подразделениями. Сотрудники исследовательских, проектных, торговых и производственных подразделений должны работать как команда, чтобы предвидеть возможные проблемы при производстве и эксплуатации продукции и предоставлении услуг.

10. Откажитесь от лозунгов, призывов и установления целей для рабочих, требующих «нуля дефектов» и выхода на новый уровень производительности. Такие призывы лишь вызывают враждебность, поскольку в большинстве случаев низкие качество и производительность на совести системы и, следовательно, не подвластны рабочим.

11. а) устраните количественные нормы и задания для рабочих в цехе. Замените их лидерством;

б) исключите управление по целям. Перестаньте управлять по числам и количественным результатам. Замените его лидерством;

12. а) разрушайте барьеры, которые лишают постоянных рабочих права гордиться своим мастерством. Мастера должны быть ответственны не за числовые показатели, а за качество;

б) ломайте барьеры, которые лишают менеджеров и инженеров их права гордиться своим мастерством. Это значит, между прочим, отказ от ежегодных аттестаций или рейтингов и от управления по целям.

13. Учредите широкую программу обучения и самосовершенствования.

14. Сделайте так, чтобы все в компании работали вместе над коренными изменениями. Преобразование - это работа для всех (Аеминг, 2007: 46-47).

Положенные в основу лекций для высшего руководства предприятиями в Японии и нацеленные на первый взгляд на систему производства, эти принципы применимы во всех сферах, в том числе могут быть адаптированы к менеджменту качества в системе образования. Отметим несколько важных идей Аеминга в понимании качества, необходимых для нашего исследования. 
«Качество» выступает как цель, но не как некий раз и навсегда обозначенный Абсолют. Призыв в п. 1 к постоянному непрерывному улучшению продукции означает подвижность характеристик качества, которое подобно динии горизонта может быть пределом стремлений человека, но окончательно не будет достигнуто, поскольку достижение определенной меры качества означает открытие новых перспектив. Непрестанное улучшение качества требует постоянного развития сотрудников, поэтому Аeминг неоднократно настаивает на необходимости повышения квалификации (п. 6, 13).

Повышение качества видится как результат стабильной работы системы управления, а снижение качества - результат сбоя в работе системы, а не влияния некоего случайного фактора $($ п. 5,10$)$. Философия качества требует системности управления, не случайно Аеминг призывает разрушать барьеры между подразделениями, чтобы их сотрудники чувствовали себя частью единой команды.

Сформулированная Аемингом Система глубинных знаний (System of Profound Knowledge), которые он считал необходимыми для любого успешного менеджера, вкдючает помимо теории систем и вариабельности теорию познания (в части понимания познавательного процесса и возможностей познания) и психологию (понимание людей, их мотивации и возможностей) (Deming, 2000).

Поэтому в п. 12 он провозглашает важность для всех участников процесса возможности гордиться своим мастерством. В системе управления качеством это подразумевает, в том числе, создание условий для проявления профессионального мастерства и лидерства в определенной сфере деятельности (п. 7,11).

Подводя итог анализа сформулированных Аемингом 14 принципов философии качества, отметим еще раз прозвучавшую идею о несводимости понятия «качество» к количественным показателям (п. 10, 11). Таким образом, качество выступает как одна из ключевых ценностей человеческого бытия, как аксиологическая категория, не имеющая, однако, раз и навсегда устоявшегося значения и по мере развития приобретающая новый смысл.

Начавшаяся с работ Аеминга «революция качества» расширяет понятие качества, поскольку сегодня это понятие используется для характеристики не только материальных объектов, обладающих качественной определенностью, но и таких социокультурных феноменов, как деятельность, услуги, блага. Появление принципиально нового подхода к осмыслению качества знаменует, например, появление такой категории, как «качество жизни». Из экономики и научно-технической сферы, где во второй половине XX в. в трудах К. Исикавы и Г. Тагути, Аж. Ажурана и Ф. Кросби были сформулированы принципы достижения и оценки качества, понятие «качество» переходит в социальную и образовательную сферу, где механизмы достижения и оценки качества создаются сегодня.

В разговоре о постулатах философии качества невозможно обойти вниманием сформулированные А. Фейгенбаумом четыре «смертных греха» в подходе к оценке качества (Фейгенбаум, 1986: 172-175). Первый «грех» он видит в провозглашении лозунгов и акценте на поверхностных изменениях. Второй - в излишней ориентации на простых сотрудников и игнорировании инженерных служб, что может привести к пренебрежению инновациями и сказаться в перспективе на системе качества. Третий «грех» - нежелание признать, что постоянного уровня качества не существует, - повторяет важную идею Аеминга о необходимости непрерывного повышения уровня качества. И наиболее фатальным предстает четвертый «грех» - переоценка автоматизации процессов, которая не обязательно приводит к повышению качества, 
так как, по мнению Фейгенбаума, большие перспективы в повышении качества раскрывают программы, основанные на человеческом факторе.

Перу Фейгенбаума принадлежит один из основных постулатов философии качества: эффективность управления качеством зависит от его планирования и осуществления на ранних стадиях производственного процесса. Комплексное управление качеством (TQM) представляет собой принципиально новый стиль руководства, порождающий новую культуру управления предприятием (Feigenbaum A., Feigenbaum D., 2009).

Таким образом, в современной философии качества «качество» представляет собой интегральную системную характеристику объекта, которая отражает выполнение всех требований к свойствам объекта. Качество невозможно измерить или исчислить. Однако качество характеризуется с помощью определенных параметров, степень выраженности которых выступает как исчисляемая категория и позволяет произвести оценку качества.

Оценка качества как системной категории, описывающей объект, ставит перед исследователем важную задачу: необходимо выявить все параметры, характеризующие качество данного объекта. Проведение процедуры оценки качества требует участия компетентных специалистов, способных оценить степень выраженности данных параметров, иначе оценка качества грозит превратиться в формальную процедуру, против чего предостерегал Э. Аеминг.

\section{ПЯТЬ УРОВНЕЙ УПРАВАЕНИЯ КАЧЕСТВОМ ОБРАЗОВАТЕАЬНОЙ АЕЯТЕАЬНОСТИ}

В высшем учебном заведении образовательная деятельность является основным процессом жизненного цикла. При этом отличием этого процесса от остальных является максимальная вовлеченность в него сотрудников образовательной организации. Представляя собой интегральный процесс в системе менеджмента качества, образовательная деятельность осуществляется на разных уровнях функционирования организации, что позволяет проводить оценку качества на каждом из этих уровней.

Можно выделить пять уровней управления качеством образовательной деятельности, для каждого из которых характерны свои механизмы контроля и оценки качества. Это: 1) уровень высшего руководства, 2) уровень учебно-методического управления, 3) уровень факультетов и кафедр, 4) уровень преподавателей и 5 ) уровень студентов, которых с точки зрения системы менеджмента качества следует рассматривать не как потребителей услуг, а как полноценных участников образовательного процесса.

Уровень высшего руководства - уровень стратегического управления качеством образовательной деятельности (начиная от приема абитуриентов и заканчивая содействием трудоустройству выпускников). В медицинском вузе образовательная деятельность взаимосвязана с научной и клинической работой, а также системными и поддерживающими процессами. Оценка качества образовательной деятельности на уровне высшего руководства значима для определения перспектив развития и прогнозирования результата деятельности вуза.

На уровне высшего руководства существует ряд механизмов оценки качества образовательной деятельности - как государственной, проводимой Министерством образования и науки и профильными министерствами, так и независимой оценки образовательной организации.

Один из механизмов государственной оценки качества представляет Мониторинг эффективности деятельности организаций высшего образования, проводимый Аепартаментом государственной политики в сфере высшего образования Министерства 
образования и науки РФ (Информационно-аналитические материалы ... , 2017: Электронный ресурс). Аля оценки качества используются исчислимые показатели.

Важнейшим показателем результативности образовательной деятельности становится трудоустройство (удельный вес выпускников, трудоустроившихся в течение календарного года, следующего за годом выпуска). Косвенным показателем результативности выступает характеристика кадрового состава (как удельный вес научнопедагогических работников (НПР), имеющих ученую степень кандидата и доктора наук, в общей численности НПР; число НПР, имеющих ученую степень, в расчете на 100 студентов). Большое внимание в мониторинге уделяется контингенту поступающих (средний балл ЕГЭ студентов, принятых на обучение на бюджетной основе и с оплатой стоимости обучения; численность принятых на обучение победителей и призеров олимпиад школьников; численность студентов, принятых на обучение по результатам целевого приема). Эти показатели, с одной стороны, характеризуют репутацию учебного заведения, а с другой - задают начальные параметры для осуществления образовательной деятельности и необходимы для стратегического планирования управления качеством.

Независимая оценка качества образовательной деятельности осуществляется согласно ст. 95 Федерального закона «Об образовании в Российской Федерации» и проводится «в целях определения соответствия предоставляемого образования потребностям физического лица и юридического лица, в интересах которых осуществляется образовательная деятельность, оказания им содействия в выборе организации, осуществляющей образовательную деятельность, и образовательной программы, повышения конкурентоспособности организаций, осуществляющих образовательную деятельность, и реализуемых ими образовательных программ на российском и международном рынках» (Об образовании ..., 2012: Электронный ресурс).

Обязательные критерии проведения независимой оценки качества образовательной деятельности зафиксированы в рекомендациях Минобрнауки РФ от 1 апреля 2015 г. (Методические рекомендации по ..., 2015: Электронный ресурс). Это четыре критерия, на основании которых сформулированы 16 показателей, представленных в Методических рекомендациях по расчету показателей независимой оценки качества образовательной деятельности организаций, осуществляющих образовательную деятельность, утвержденных Минобрнауки РФ 15 сентября 2016 г. (Методические рекомендации по ..., 2016: Электронный ресурс):

- открытость и доступность информации об организациях, осуществляющих образовательную деятельность;

- комфортность условий, в которых осуществляется образовательная деятельность;

- доброжелательность, вежливость, компетентность работников;

- удовлетворенность качеством образовательной деятельности организаций, осуществляющих образовательную деятельность.

Второй уровень управления качеством образовательной деятельности представляет учебно-методическое управление, в задачи которого входит создание в вузе единого информационно-образовательного пространства, которое обеспечивает слаженную работу всех факультетов и кафедр вуза. Границы пространства задаются извне и в самом вузе: с одной стороны, это нормативные документы государственного уровня, а другой - внутренняя нормативная база. Оценка качества на данном уровне означает выявление соответствия/несоответствия внутренней нормативной документации 
внешней. На этом уровне осуществляется важный вклад в создание системы управления качеством - определение стратегических результатов образовательной деятельности (формирование компетенций, системы знаний, умений и навыков у студентов), унификация предъявляемых к студентам требований, форм и методов контроля.

Контроль и оценка качества на уровне учебно-методического управления достаточно формализованы и наглядны. На третьем же уровне - уровне кафедр и факультетов - контроль и оценка качества представляют серьезную, хотя и вполне решаемую проблему. На этом уровне образовательная деятельность наполняется конкретным содержанием в соответствии с федеральным стандартом высшего образования. Здесь организуется и реализуется учебный процесс, создаются эффективные условия Аля освоения обучающимися компетенций. От качества деятельности на данном уровне зависит целостность реализации учебной деятельности всего вуза.

Ежегодно на уровне факультетов проводится анализ результативности и эффективности образовательной деятельности на основании формализованных показателей, этот анализ включает в себя сводную информацию по результативности и әффективности работы кафедр. Неотъемлемой чертой складывающейся таким образом системы управления качеством является планирование деятельности кафедр и факультетов, в том числе формулировка целей в области качества подразделений на текущий год. Цели определяются исходя из стратегических и тактических целей учебного заведения, сформулированных в пятилетнем плане развития и целях академии на год.

Аля независимой оценки качества на уровне факультетов и кафедр используется создаваемый в настоящее время в соответствии со ст. 96 Федерального закона «Об образовании в Российской Федерации» механизм профессионально-общественной аккредитации образовательных программ.

Эксперимент по независимой оценке знаний обучающихся в образовательных организациях высшего образования в рамках проведения промежуточной аттестации, проведенный в 2017 г. Федеральной службой по надзору в сфере образования и науки РФ, является механизмом независимой оценки качества реализации образовательных программ на уровне факультетов и кафедр. Эксперимент нацелен на объективную и независимую оценку знаний студентов с участием экспертов и представителей экспертных организаций, а также общественных организаций.

Механизмом компетентной оценки качества образовательной деятельности на уровне кафедр и факультетов является система внутренних аудитов. Специфика данного подхода состоит в создании команды внутренних аудиторов, преподающих дисциплины, относящиеся к разным областям научного знания, что позволяет создать единую модель преподавания в вузе, невзирая на традиционно признаваемое разделение дисциплин на гуманитарные и естественно-научные, а в условиях медицинского вуза еще и на теоретические и клинические.

Важным этапом проведения внутреннего аудита является проверка наличия документации, но это создает соблазн для превращения внутренних аудитов в формальную процедуру. Аля реальной работы внутренних аудитов в системе оценки качества необходимо определить параметры, влияющие на качество образовательной деятельности.

На основе приведенных в рекомендациях Министерства образовании и науки по независимой оценке качества образовательной деятельности критериев оценки качества можно сформулировать следующие показатели оценки качества работы структурных подразделений. 
1. Открытость и доступность информации о ходе учебного процесса (доступность расписания занятий и консультаций; информации о текущей успеваемости учащихся; информации о требованиях к освоению дисциплины, методах и формах контроля; методических разработок и учебных пособий).

2. Нацеленность образовательной деятельности на формирование личностно-профессиональной компетентности обучающихся (направленность фондов оценочных средств на оценку уровня сформированности заявленных компетенций; списки практических навыков по преподаваемым дисциплинам, алгоритмы выполнения практических умений).

3. Нацеленность образовательной деятельности на раскрытие потенциала обучающихся (использование интерактивных методов обучения; методическое обеспечение самостоятельной работы студентов и критерии оценки; возможность реализации научно-исследовательского потенциала обучающихся; практика формирования профессионально важных качеств обучающихся в рамках воспитательной работы) (Борзов, Корягина, Жуколина, 2016: 198).

Управление качеством на уровне преподавателя нацелено на осуществление ключевой задачи образовательного процесса - сопровождения студентов на пути формирования их личностно-профессиональной компетентности. Контроль качества на данном этапе определяется прежде всего профессиональным мастерством самого педагога, его осмыслением хода учебного процесса и достижения запланированных результатов. Но для объективизации контроля качества в вузе существует практика взаимопосещений преподавателями лекций и семинаров, которая позволяет преподавателям не только повысить собственное профессиональное мастерство, но и выстроить единую модель преподавания дисциплины либо ряда взаимосвязанных дисциплин, нивелируя возможные научные разногласия по ключевым проблемам современной науки.

Важным механизмом влияния профессорско-преподавательского состава на управление качеством образовательного учреждения является мониторинг удовлетворенности условиями труда, позволяющий обозначить «проблемные поля» и «точки роста» в развитии.

Системным механизмом оценки качества образовательной деятельности на уровне преподавателей является проводимый в ряде вузов рейтинг профессорско-преподавательского состава или мониторинг эффективности деятельности педагогических работников. С учетом наиболее важных для вуза сфер деятельности выделяются значимые показатели, на основании которых проводится оценка результативности и эффективности деятельности педагогических работников. Вопрос о критериях оценки работы преподавателей предстает весьма дискуссионным, поскольку он находится в компетенции вуза, и каждый вуз определяет значимые для него критерии. Среди всех выделяемых исследователями подходов к оценке деятельности преподавателей (изучение мнения студентов о преподавателе и учебном процессе, сопоставление результатов обучения студентов или другие механизмы оценки педагогического мастерства) рейтинговый подход предстает наиболее эффективным (Васильева, 2005: 50-57). Он призван отследить индивидуальные успехи преподавателей и мотивировать их на дальнейший профессиональный рост, реализуя обозначенный Аемингом курс на лидерство как важный аспект управления качеством. Системное обобщение этих данных, в свою очередь, приводит к оценке качества образовательной деятельности на уровне высшего руководства. 
Базовый уровень управления качеством образовательной деятельности - уровень студентов, на чье личностно-профессиональное становление нацелен образовательный процесс. В системе управления качеством студенты выступают и как объект, и как субъект оценивания. Система промежуточной и итоговой аттестации, методы рейтинговой оценки студентов дают важную информацию о качестве реализации образовательной деятельности. Но и сами студенты могут влиять на учебный процесс через мониторинг удовлетворенности образовательной деятельностью. Мониторинг представляет важную информацию для оценки качества: возможность выбора дисциплины обучающимся, удовлетворенность качеством лекций, практических занятий, условиями реализации учебного процесса, возможность прокладывать индивидуальный образовательный маршрут (Борзов и др., 2016: 56-57).

\section{ЗАКАЮЧЕНИЕ}

А. Фейгенбаум определяет качество как способ мышления, важнейшим параметром оценки качества является осознанность. Управление качеством образовательной деятельности предполагает осознание механизмов протекания всех процессов жизненного цикла вуза на всех уровнях и всеми вовлеченными сторонами.

\section{СПИСОК АИТЕРАТУРЫ}

Федеральный закон от 29 декабря 2009 г. № 273-Ф3 «Об образовании в Российской Федерации» (2012) [Электронный ресурс]// Российская газета : [офиц. сайт]. URL: https://rg.ru/2012/ 12/30/obrazovanie-dok.html (Аата обращения: 31.08.2017).

Аристотель (2016) Категории. М. : Аенанд. 80 с.

Борзов, Е. В., Корягина, И. И., Вотякова, О. И., Курылёва, Н. В. (2016) Управление качеством образования на основе мониторинговых исследований // Образование и наука. №6. C. $42-61$.

Борзов, Е. В., Корягина, И. И., Жуколина, М. В. (2016) Оценка качества реализации образовательной деятельности сквозь призму философского понимания качества // Новые технологии оценки качества образования : сб. материалов XI Форума экспертов в сфере профессионального образования / под общ. ред. Г. Н. Мотовой. М. : Гильдия экспертов в сфере профессионального образования. 331 с. С. 193-199.

Васильева, Е. Ю. (2005) Оценка деятельности преподавателей в российских и зарубежных вузах. Архангельск : Северный государственный медицинский университет. 165 с.

Гегель, Г. В. Ф. (2007) Наука логики. М. : Наука. 802 с.

Аеминг, Э. (2007) Выход из кризиса. Новая парадигма управления людьми, системами и процессами. М. : Альпина Бизнес Букс. 370 с.

Информационно-аналитические материалы по результатам проведения мониторинга эффективности деятельности образовательных организаций высшего образования [Электронный peсурс] // Главный информационно-вычислительный центр, Министерство образования и науки. URL: http://indicators.miccedu.ru/monitoring/?m=vро (дата обращения: 31.08.2017).

Кант, И. (2015) Критика чистого разума. М. : Академический проект. 568 с.

Кант, И. (2008) Пролегомены ко всякой будущей метафизике, могущей возникнуть в смысле науки. М. : Академический проект. 176 с.

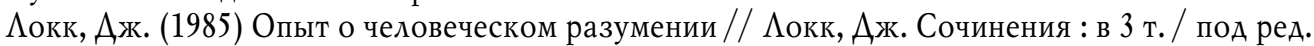
И. С. Нарского. М. : Мысль. Т. 1.623 с.

Методические рекомендации по проведению независимой оценки качества образовательной деятельности организаций, осуществляющих образовательную деятельность, утв. Минобрнауки РФ, от 1 апреля 2015 г. (2015) [Электронный ресурс]// Министерство образования и науки Российской Федерации. 12 апреля. URL: Минобрнауки.рф/документы/ 5474 (дата обращения: 31.08.2017). 
Методические рекомендации по расчету показателей независимой оценки качества образовательной деятельности организаций, осуществляющих образовательную деятельность, утв. Минобрнауки РФ 15 сентября 2016 г. (2016) [Электронный ресурс]// Министерство образования и науки Российской Федерации. 15 сентября. URL: минобрнауки.рф/документы/8787 (дата обращения: 31.08.2017).

Фейгенбаум А. (1986) Контроль качества продукции. М. : Экономика. 472 с.

Deming, W. E. (2000) Out of the crisis. Cambridge, MA: ed. MIT Press. 522 p.

Feigenbaum, A. V., Feigenbaum, D. S. (2009) The power of management innovation : 24 keys for sustaining and accelerating business growth and profitability. New York : McGraw-Hill. 120 p.

Аата поступления: 05.09.2017 2.

\section{ASSESSMENT OF THE QUALITY OF EDUCATIONAL ACTIVITY AS AN EMBODIMENT \\ OF THE PHILOSOPHY OF QUALITY POSTULATES}

\section{I. KORYAGINA, M. V. ZHUKOLINA}

Federal State Budgetary Educational Institution of Higher Education «IVAnovo State Medical Academy» OF THE MINISTRY OF HEALTHCARE OF THE RUSSIAN FEDERATION

The purpose of the presented research is to analyse the concept of «quality» in history and modernity, to analyse approaches to the assessment of the quality of educational activity at higher education institutions, and to develop an integrated concept of quality assessment. The research methodology includes the analysis and synthesis of empirical experience, methods of included observation, and processing of accumulated data.

The paper reviews the development of the concept «quality» in the history of philosophy; determines the key concepts of meaning and the evolution of subject matter. The problems of quality control are identified according to its philosophical perception: the inability to put quality down to quantitative characteristics, the idea of quality as a constantly improving value, the systematicity and multidimensionality of quality. It is necessary to identify five levels for the quality control in educational process: from the top management level through to the learning methods management level and the level of departments and faculties, to the basic level of professors and students. At the level of top management, the authors presented the existing practices for assessing the quality of educational activity by state authorities and independent quality assessment, and analysed the possibility of spreading these methods to other levels of educational activity.

The paper systematizes the mechanisms for assessing the quality of educational activities applied at each level and shows the possibility of their integration in order to obtain the most objective assessment, taking into account the requirements of all interested parties.

The study reveals the effectiveness of the applied methods of quality control, and presents the way of their integration within the quality management system of higher education.

Keywords: quality; philosophy of quality; quality management; quality assessment; educational activity; structure of educational activity

\section{REFERENCES}

Ob obrazovanii v Rossiiskoi Federatsii : feder. zakon Ros. Federatsii ot 29.12.2012 № 273-FZ; priniat Gos. Dumoi Feder. Sobr. Ros. Federatsii 21.12.2012; odobr. Sovetom Federatsii Feder. Sobr. Ros. Federatsii 26.12.2012. Rossiiskaia gazeta [online] Available at: https://rg.ru/2012/12/30/obrazovanie-dok.html (accessed 31.08.2017) (In Russ.).

Aristotel' (2016) Kategorii. Moscow, Lenand Publ. 80 p. (In Russ.).

Borzov, E. V., Koriagina, I. I., Votiakova, O. I. and Kuryleva, N. V. (2016) Upravlenie kachestvom obrazovaniia na osnove monitoringovykh issledovanii. Obrazovanie $i$ nauka, no. 6, pp. 42-61. (In Russ.).

Borzov, E. V., Koriagina, I. I. and Zhukolina, M. V. (2016) Otsenka kachestva realizatsii obrazovatel'noi deiatel'nosti skvoz' prizmu filosofskogo ponimaniia kachestva. Novye tekbnologii otsenki kachestva obrazovaniia : sbornik materialov XI Foruma ekspertov v sfere professional'nogo obra- 
zovaniia / ed. by G. N. Motova. Moscow, Gil'diia ekspertov v sfere professional'nogo obrazovaniia. 331 p. Pp. 193-199. (In Russ.).

Vasil'eva, E. Iu. (2005) Otsenka deiatel'nosti prepodavatelei v rossiiskikb i zarubezhnykb vuzakb. Arkhangel'sk, Severnyi gosudarstvennyi meditsinskii universitet. 165 p. (In Russ.).

Hegel, G. W. (2007) Nauka logiki. Moscow, Nauka Publ. 802 p. (In Russ.).

Deming, W. E. (2007) Vykhod iz krizisa. Novaia paradigma upravleniia liud'mi, sistemami $i$ protsessami. Moscow, Al'pina Biznes Buks Publ. 370 p. (In Russ.).

Informatsionno-analiticheskie materialy po rezul'tatam provedeniia monitoringa effektivnosti deiatel'nosti obrazovatel'nykh organizatsii vysshego obrazovaniia. Glavnyi informatsionno-vychislitel'nyi tsentr, Ministerstvo obrazovaniia $i$ nauki [online] Available at: http://indicators.miccedu.ru/monitoring/?m=vpo (accessed 31.08.2017). (In Russ.).

Kant, I. (2015) Kritika chistogo razuma. Moscow, Akademicheskii proekt Publ. 568 p. (In Russ.).

Kant, I. (2008) Prolegomeny ko vsiakoi budushchei metafizike, mogushchei vozniknut'v smysle nauki. Moscow, Akademicheskii proekt Publ. 176 p. (In Russ.).

Locke, J. (1985) Opyt o chelovecheskom razumenii. In: Locke, J. Socbineniia / Ed. by I. S. Narskii. Moscow, Mysl' Publ. Vol. 1. 623 p.

Metodicheskie rekomendatsii po provedeniiu nezavisimoi otsenki kachestva obrazovatel'noi deiatel'nosti organizatsii, osushchestvliaiushchikh obrazovatel'nuiu deiatel'nost' Minobrnauki RF ot 1 aprelia 2015 goda. Ministerstvo obrazovaniia i nauki Rossiiskoi Federatsii [online] Available at: minobrnauki.rf/dokumenty/5474 (accessed 31.08.2017). (In Russ.).

Metodicheskie rekomendatsii po raschetu pokazatelei nezavisimoi otsenki kachestva obrazovatel'noi deiatel'nosti organizatsii, osushchestvliaiushchikh obrazovatel'nuiu deiatel'nost' Minobrnauki RF ot 15 sentiabria 2016 goda. Ministerstvo obrazovaniia $i$ nauki Rossiiskoi Federatsii [online] Available at: minobrnauki.rf/dokumenty/8787 (accessed 31.08.2017). (In Russ.).

Feigenbaum, A. (1986) Kontrol' kachestva produktsii. Moscow, Ekonomika Publ. 472 p.

Deming, W. E. (2000) Out of the crisis. Cambridge, MA, MIT Press. 522 p.

Feigenbaum, A. V. and Feigenbaum, D. S. (2009) The power of management innovation : 24 keys for sustaining and accelerating business growth and profitability. New York, McGraw-Hill. 120 p.

Submission date: 05.09.2017.

Корягина Ирина Ивановна - кандидат педагогических наук, помощник ректора по качеству, доцент кафедры психологии и педагогики Ивановской государственной медицинской академии Министерства здравоохранения России. Адрес: 153012, Россия, г. Иваново, Шереметьевский проспект, А. 8. Тел.: +7 (4932)41-77-94. Эл. адрес: koryaginairina@mail.ru

Жуколина Мария Викторовна - кандидат философских наук, доцент кафедры гуманитарных наук Ивановской государственной медицинской академии Министерства здравоохранения России. Адрес: 153012, Россия, г. Иваново, Шереметьевский проспект, д. 8. Тел.: +7 (4932) 41-77-94. Эл. aspec: bonvenu@rambler.ru

Koryagina Irina Ivanovna, Candidate of Pedagogy, Rector Assistant for Quality, Associate Professor, Department of Psychology and Pedagogy, Federal State Budgetary Educational Institution of Higher Education «Ivanovo State Medical Academy» of the Ministry of Healthcare of the Russian Federation. Postal address: 8, Sheremetevsky Ave., Ivanovo, Russian Federation 153012. Tel.: +7 (4932) 41-77-94. E-mail: koryaginairina@mail.ru

Zhukolina Maria Viktorovna, Candidate of Philosophy, Associate Professor, Department of the Humanities, Federal State Budgetary Educational Institution of Higher Education «Ivanovo State Medical Academy» of the Ministry of Healthcare of the Russian Federation. Postal address: 8, Sheremetevsky Ave., Ivanovo, Russian Federation 153012. Tel.: +7 (4932) 41-77-94. E-mail: bonvenu@rambler.ru 